\title{
Exostosis subungueal y su diagnóstico diferencial: A propósito de un caso
}

\author{
María Teresa Dossi C. ', Catherina Moll-Manzur ${ }^{2}$
}

Resumen: Los tumores y pseudotumores ungueales representan un desafío diagnóstico, principalmente, dada la compleja anatomía de la uña y la apariencia clínica similar de estas lesiones. La exostosis subungueal es una entidad de baja frecuencia que debe considerarse en el diagnóstico de las masas subungueales. No es un tumor verdadero, sino crecimiento anormal de hueso o una calcificación de tejido cartilaginoso. En el siguiente artículo, se comunica el caso de una exostosis subungueal y realizamos una breve discusión, enfatizando los diagnósticos diferenciales, principalmente el melanoma subungueal, que debe sospecharse siempre y derivarse en forma precoz.

Palabras clave: exostosis; exostosis subungueal; enfermedades de las uñas.

Abstract: Nail tumors and pseudotumors represent a diagnostic challenge, mainly due to the complex anatomy of the nail and similar clinical appearance of these lesions. Subungual exostosis is an entity of low frequency, which should be considered in the differential diagnoses of subungual masses. It is not a true tumor, but an overgrowth of bone or cartilage tissue calcification. In the following article, we report the case of a subungual exostosis and perform a brief discussion, emphasizing the differential diagnoses, including the subungual melanoma, which should always be suspected and referred in a timely manner.

Keywords: Exostoses; subungual exostoses; nail diseases.

Fecha de envío: 30 de 0ctubre de 2015 - Fecha de aceptación: 31 de Mayo de 2016

\section{Introducción}

La exostosis subungueal (ES) es una entidad poco frecuente, considerada como un crecimiento anormal de hueso o una calcificación de tejido cartilaginoso. Su importancia clínica radica en que puede ser una fuente de dolor y deformidad, incluso permanente, de la lámina ungueal. Además, su diagnóstico diferencial es amplio e incluye tumores malignos como el melanoma subungueal, que tienen un mal pronóstico y que han de sospecharse siempre y derivar de forma precoz.

\section{Caso clínico}

Paciente de sexo femenino de 17 años de edad, sin antecedentes de importancia. Acudió a consulta dermatológica por presentar una lesión dolorosa de 5 meses de evolución, de crecimiento lento, localizada en el ortejo mayor derecho. No presentaba historia de traumatismo local, ni episodios de sangrado o supuración. El examen de piel y fanéreos mostró la presencia de uña distrófica, con un nódulo firme de aproximadamente $1 \mathrm{~cm}$ de diámetro mayor, localizado en la superficie dorsomedial distal del ortejo mayor derecho (figura 1).
Las otras uñas no presentaban alteraciones y el resto del examen físico era normal. Se sospechó inicialmente un tumor glómico frente a un melanoma maligno nodular amelanótico. La ecotomografía resultó compatible con una ES asociada a tejido granulatorio perilesional (figura 2). Los hallazgos radiográficos se aprecian en la figura 3. Se decidió realizar una resección quirúrgica de la ES del ortejo mayor derecho. La histopatología confirmó el diagnóstico, encontrándose hiperqueratosis y tejido óseo con proceso reparativo, compatible con ES. La paciente evolucionó sin complicaciones postoperatorias y sin recurrencia de lesión a 6 meses de seguimiento.

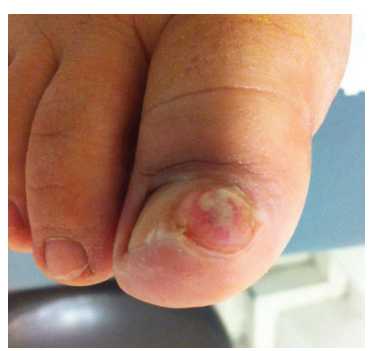

Figura 1: Apariencia clínica de la exostosis. Nódulo firme localizado en la superficie distal del ortejo mayor derecho.

(1) Departamento de Dermatología, Facultad de Medicina, Pontificia Universidad Católica de Chile

(2) Interna de Medicina, Facultad de Medicina, Pontificia Universidad Católica de Chile

Autor de correspondencia: mtdossi@gmail.com 


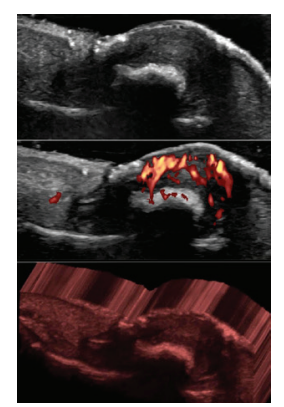

Figura 2: Ultrasonografía de ortejo mayor derecho. compatible con una exostosis subungueal, asociada a tejido de aspecto inflamatorio y granulomatoso en la periferia y cambios distróficos secundarios a nivel de la placa ungueal.

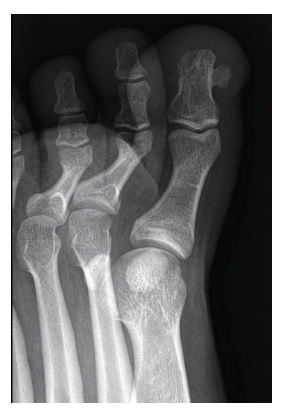

Figura 3: Radiografía oblicua de ortejo mayor derecho. Lesión exofítica radio-opaca en la superficie distal de la primera falange distal. No hay evidencia de disrupción cortical.

\section{Discusión:}

La ES es una entidad poco frecuente, considerada como un crecimiento anormal de hueso o una calcificación de tejido cartilaginoso (Wortsman et al., 2010). Suele aparecer en los niños y en adultos jóvenes, característicamente, en la segunda y tercera década de la vida (Morais, 2013; Ward \& Dittmer, 2013). Su fisiopatología no se conoce con claridad, sin embargo, se cree que corresponde a una reacción metaplásica, con osificación endocondral, tras microtraumas repetidos o infecciones crónicas (llyas et al., 2001; Morais, 2013; Ward \& Dittmer, 2013; DaCambra et al., 2014). La mayoría de las veces, compromete los pies, especialmente el dorso distal del ortejo mayor. Clínicamente se manifiesta como un nódulo firme doloroso rosado, de crecimiento lento, de localización periungueal o subungueal, asociado a alteraciones ungueales, como onicolisis, onicodistrofia, onicocriptosis, e incluso hiperqueratosis subungueal. Además, pueden producirse alteraciones de los tejidos blandos, con infección secundaria y la formación de un granuloma piogénico. Como exploraciones complementarias, que sirven para confirmar el diagnóstico, se encuentran la ultrasonografía doppler y la radiografía simple. La ultrasonografía doppler aumenta la certeza diagnóstica clínica del ES de un 23\% a un 100\% (Wortsman et al., 2010). En este examen, el ES aparece como una estructura hiperecoica, con refuerzo acústico posterior, localizada debajo de la lámina ungueal, a la que desplaza hacia arriba. En la radiografía simple, se observa típicamente una lesión exofítica radio-opaca pedunculada o sésil, localizada en la superficie dorsomedial de la falange distal, y sin evidencia de disrupción cortical (Ward \& Dittmer, 2013; DaCambra et al., 2014).

Como diagnósticos diferenciales de las masas subungueales, deben considerarse principalmente, los tumores benignos y malignos de origen ungueal o periungueal.

Tumor glómico: es una neoplasia vascular benigna rara, que se presenta como una pápula o nódulo rojo-violáceo, que característicamente duele en forma paroxística con el frío o la presión. Afecta la lamina ungueal distal y puede presentar eritroniquia y distrofia ungueal. Los hallazgos ultrasonográficos más característicos son: la presencia de un nódulo bien definido e hipoecoico, con un componente hipervascular profuso, que afecta la matriz ungueal y la remodelación cortical activa de hueso de la falange distal. El estudio histopatológico muestra una masa sólida de células glómicas, vasos sanguíneos y células musculares lisas.

Tumores fibrosos: son tumores benignos derivados del tejido conectivo, que más frecuentemente se originan de la matriz ungueal, aunque también pueden surgir del lecho ungueal o del pliegue ungueal proximal, y extenderse hacia la lamina ungueal. Tienen una tasa de crecimiento lenta y generalmente no duelen. Existen varios tipos de fibromas ungueales.

Quiste digital mixoide o quiste mucinoso: clínicamente se presenta como un nódulo indolente translúcido en el dorso del dedo, entre la articulación interfalángica distal y el pliegue ungueal proximal. Por compresión de la matriz, puede haber un surco longitudinal en la lámina ungueal, así como también el drenaje espontáneo de un material viscoso. A la ultrasonografía, generalmente se aprecia como un nódulo anecoico avascular, ovalado o redondeado, con refuerzo acústico posterior. El diagnóstico de certeza se realiza por medio de la histopatología, en la cual se aprecia una colección de fluido mucinoso sin revestimiento epitelial, como un pseudoquiste.

Quiste sinovial: presenta una clínica similar al quiste mixoide, pero aparece en pacientes con cambios degenerativos articulares o sinovitis. A diferencia del quiste mixoide, presenta una comunicación con las estructuras de la articulación interfalángica distal. El diagnóstico de certeza se realiza por medio de la histopatología.

Granulomas: son tumores vasculares benignos, que se presentan como un nódulo de rápido crecimiento, compuesto de tejido granulatorio rojo y friable, que sangra fácilmente. Generalmente, ocurren secundariamente a inflamación crónica o traumática del lecho ungueal. El diagnóstico se confirma por medio de la histopatología. 
Melanoma subungueal: pese a que es una variante poco común del melanoma, es el principal diagnóstico diferencial a descartar, debido a su comportamiento agresivo y mal pronóstico, si se diagnostica en forma tardía. Por ello, debe sospecharse y derivarse de forma oportuna. Generalmente, aparece en pacientes de $50 \mathrm{a}$ 70 años de edad, aunque también puede ocurrir en más jóvenes. Debe sospecharse ante la aparición de una melanoniquia longitudinal, con signo de Hutchinson, distrofia ungueal o la aparición de un tumor subungueal (amelanótico), que puede sangrar. Si bien la dermatoscopia puede ser de utilidad, debe siempre realizarse una biopsia de la matriz, lecho ungueal y de la lámina ungueal. A la histopatología, se observa característicamente un aumento del número de melanocitos, con múltiples núcleos, atipia y distribución pagetoide, con o sin invasión estromal. En muchos casos, se observa melanina en el tercio inferior de la epidermis de la matriz ungueal.

\section{Carcinoma de células escamosas (incluyendo la enfermedad de}

Bowen): es el tumor maligno más frecuente de la uña. Las formas de presentación son variadas e incluyen hiperqueratosis, onicolisis, paroniquia, distrofia de la lámina ungueal, eritroniquia longitudinal e incluso la presencia una masa subungueal. El diagnóstico debe confirmarse por medio de la histopatología.

En general, la ES se maneja con extirpación quirúrgica, dada la naturaleza progresiva de esta entidad. Una revisión de casos clínicos encontró que la escisión marginal completa mitigaría el riesgo de recurrencia a un 4\%, sin embargo, la calidad de la evidencia es limitada, y no hay consenso sobre la mejor técnica que derive en una menor tasa de recurrencia y menores complicaciones cosméticas (DaCambra et al., 2014). Asimismo, se sugiere realizar una delicada separación de las estructuras del lecho ungueal subyacente $y$, posteriormente, un adecuado manejo de la herida, para evitar la onicodistrofia que es una complicación común del tratamiento quirúrgico (DaCambra et al., 2014).
La aparición de una masa ungueal en un paciente es un desafío diagnóstico, incluso para el dermatólogo, dada la apariencia clínica similar de estos tumores y pseudotumores ungueales. El médico no especialista debe reconocer este tipo de lesiones y derivar de forma oportuna, en pos de tener un diagnóstico de certeza. En este sentido, si bien la ecotomografía puede ser de utilidad para aumentar la sensibilidad diagnóstica, sin embargo, para la confirmación del diagnóstico, se requiere la histopatología.

\section{Contribuciones y reconocimientos}

María Teresa Dossi C: revisión y redacción del manuscrito. Catherina Moll-Manzur: redacción del manuscrito. Fuentes de financiamiento: ninguna. Conflictos de interés: ninguno de los autores presenta algún conflicto de interés. Se obtuvo permiso del paciente para la toma de fotografías clínicas.

\section{Referencias}

DaCambra MP, Gupta SK \& Ferri-de-Barros F. (2014). Subungual exostosis of the toes: a systematic review. Clinical orthopaedics and related research 472, 1251-1259.

Ilyas W, Geskin L, Joseph AK \& Seraly MP. (2001). Subungual exostosis of the third toe. Journal of the American Academy of Dermatology 45, S200-201.

Morais P. (2013). Subungual nodule of the great toe. Australian family physician 42, 213-215.

Ward CM \& Dittmer A. (2013). Subungual exotosis of the finger: case report and review of the literature. The lowa orthopaedic journal 33, 228-231.

Wortsman X, Wortsman J, Soto R, Saavedra T, Honeyman J, Sazunic I \& Corredoira Y. (2010). Benign tumors and pseudotumors of the nail: a novel application of sonography. Journal of ultrasound in medicine : official journal of the American Institute of Ultrasound in Medicine 29, 803-816. 